\title{
Ultra Wide Wavelength Multiplexing/Demultiplexing Conventional Arrayed Waveguide Grating (AWG) Devices for Multi Band Applications
}

\author{
Abd El-Naser A. Mohamed ${ }^{1}$, Ahmed Nabih Zaki Rashed ${ }^{2 *}$, and Mahmoud M. A. Eid ${ }^{3}$ \\ 1,2,3 Electronics and Electrical Communications Engineering Department \\ Faculty of Electronic Engineering, Menouf 32951, Menoufia University, EGYPT \\ 2*E-mail: ahmed_733@yahoo.com
}

\begin{abstract}
This paper has proposed new materials based conventional arrayed waveguide grating (AWG) devices such as pure silica glass $\left(\mathrm{SiO}_{2}\right)$, Lithium niobate $\left(\mathrm{LiNbO}_{3}\right)$, and gallium aluminum arsenide $\left(\mathrm{Ga}_{(1-\mathrm{x})} \mathbf{A l}_{(\mathrm{x})} \mathrm{As}\right)$ materials for multiplexing and demultiplexing applications in interval of $1.45 \mu \mathrm{m}$ to $1.65 \mu \mathrm{m}$ wavelength band, which including the short, conventional, long, and ultra long wavelength band. Moreover we have taken into account a comparison between these new materials within operating design parameters of conventional AWG devices such as diffraction order, length difference of adjacent waveguides, focal path length, free spectral range or region, maximum number of input/output wavelength channels, and maximum number of arrayed waveguides. As well as we have employed these materials based AWG to include Multi band applications under the effect of ambient temperature variations.
\end{abstract}

Index Terms- Diffraction order; Multi band wavelengths; Ultra long wavelength band; Arrayed waveguide grating (AWG); Multiplexing/Demultiplexing applications.

\section{INTRODUCTION}

The increase on the demand of these services, related to the deregulation processes in USA and Europe in the telecommunications sector [1], has motivated the need of telecommunication transport networks with higher capacity and flexibility. Hence, the general trend in the all the disciplines of telecommunications in the last decade, has been the increase of the capacity and flexibility of existing networks, and the deployment of new networks to cope with the mentioned demand. Therefore, new technologies have appeared and been developed in this period. The discipline of photonics and fiber optic communications has attracted a lot of interest, and has been one of the fields with major increase during this period. Several photonics and optics technologies have made feasible the increase and development of the capacity and flexibility in existing and new telecommunications networks. Nevertheless, two optic technologies have been recognized as the main contributors. First, optical amplification, which has enabled optical fiber transmission systems with higher repeater spacing. Second [2], wavelength division multiplexing, WDM, which has been first used to increase the transmission capacity of point to point optical fiber links, by using serveral wavelengths in the same fiber, to transmit several independent information channels. Optical Raman, Erbium doped and semiconductor amplifiers can regenerate several optical channels at the same time, avoiding the demultiplexer and optoelectronic conversion of each one of the channels in a WDM technique [2, 3].

Nevertheless, the use of multiple wavelengths within a fiber, i.e. WDM, has also revealed the possibility of what today is known as all-optical networks, in which the network operations are performed directly in the optical domain, without optoelectronic conversion. The latter has posed several challenges to optics engineers, which can be summarized in the following: the need to design components and systems capable of performing alloptical processing of WDM signals. The term processing encompasses several actions, as for instance generation, combination [4], separation and modification of WDM signals and the individual channels that form the WDM set. Accordingly, the improvement of already existing active and passive optical devices, and the creation of new ones has been a must to perform the mentioned processing. Hence, a lot of efforts have been invested by research institutions and companies to provide cheap devices for WDM applications to the telecommunications [5].

In the present study, we have employed three different materials based conventional AWG for multiwavelength bands for multiplexing and demultiplexing techniques for multi band applications. Also we are taken into account the physical operating parameters of materials based AWG over wide range of the affecting parameters under the temperature variations from room temperature to $65^{\circ} \mathrm{C}$.

\section{GENERAL DESCRIPTION OF CONVENTIONAL AWG MODEL}

AWG is an optical device that can separate the channels of a WDM set, or if operated reversely, combine channels of different wavelengths to form a WDM set, as shown in Fig. 1. (a). From left to right in the figure, the channels in the input port are separated to the output ports. Conversely, the device operation can be described from right to left. The channels with different 
wavelengths present as inputs in the ports at the right hand side of the device, are combined in the port on the left hand side. AWG is the wavelength dependency, together with spatial separation/combination. In fact [6], the AWG can be regarded as having a bank of pass band filters, where each filter allows a channel to pass depending on its wavelength is represented in Fig. 1. (b). Thus, the basic application of an AWG is the combination and separation of wavelengths, multiplexer and demultiplexer respectively. The AWG is a passive optical component, and the WDM channels experience some insertion loss, as in other type of optical filters.

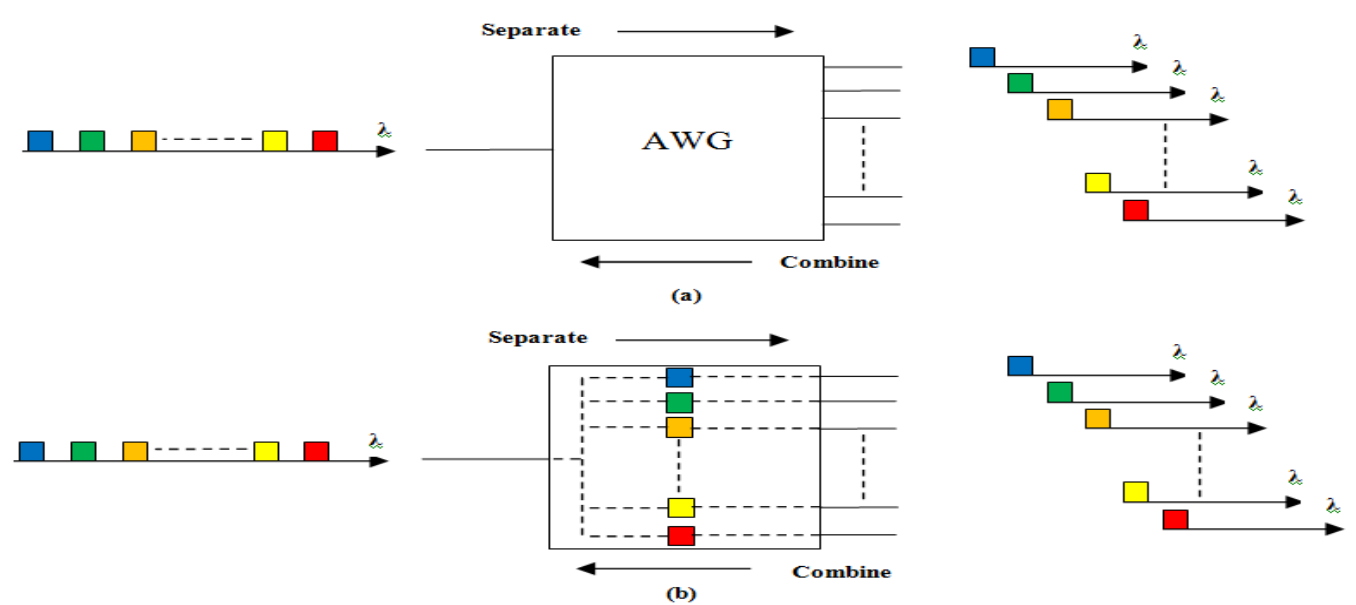

Fig. 1. Separation/combination of channels from/to a WDM set with an AWG (a), and illustration of the AWG as a bank of pass band filters (b).

The number of WDM channels that an AWG can handle, and their spacing, depends on the design of the device. The internal construction of an AWG is based in optical waveguides laid over a solid substrate. Hence, the AWG is an integrated-optic component belonging to the family of planar devices, known as Planar Light wave Circuits,
PLC. The waveguide arrangement is shown in Fig. 2. There are input waveguides that may be connected to fibers. The light at the input, formed by several wavelengths, is coupled to the arrayed waveguides by means of a slab coupler, which is also known as free propagation region.

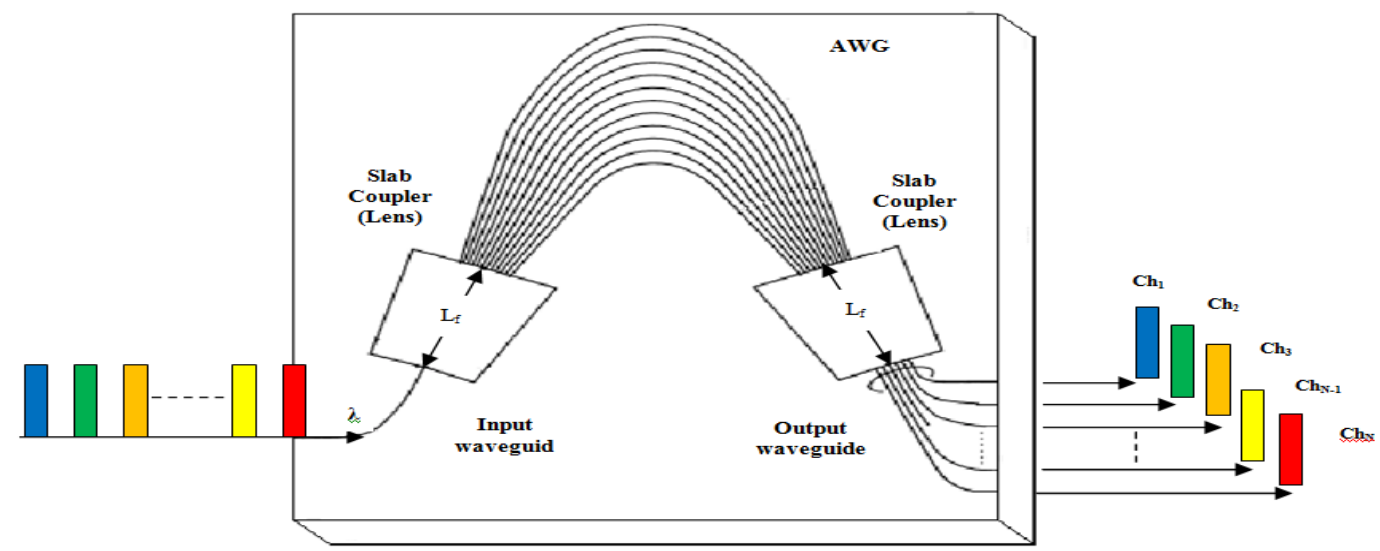

Fig. 2. AWG waveguide layout.

The arrayed waveguides have different lengths, specifically; the path length difference between adjacent waveguides is constant. The different wavelengths of the light experience different phase changes within the arrayed waveguides. The latter, combined with the second slab coupler, produces the spatial separation of the wavelengths composing the light incoming to the device [7].

\section{MODELING BASICS AND ANALYSIS}

III. 1. MATERIALSBASED ARRAYED WAVEGUIDE GRATING

A) PURE SILICA GLASS (SIO2) BASED MATERIAL

The refractive index of this waveguide is cast under the Sellemier equation as the following [8]:

$$
n^{2}=1+\frac{A_{1} \lambda^{2}}{\lambda^{2}-A_{2}^{2}}+\frac{A_{3} \lambda^{2}}{\lambda^{2}-A_{4}^{2}}+\frac{A_{5} \lambda^{2}}{\lambda^{2}-A_{6}^{2}}
$$

The set of parameters is recast and dimensionally adjusted as: $\mathrm{A}_{1}=0.691663, \mathrm{~A}_{2}=\mathrm{a}_{2} \mathrm{~T} ; \mathrm{a}_{2}=\left(0.0684043 / \mathrm{T}_{\mathrm{o}}\right)$, $\mathrm{A}_{3}=0.4079426, \quad \mathrm{~A} 4=\mathrm{a}_{4} \mathrm{~T} ; \mathrm{a}_{4}=\left(0.1162414 / \mathrm{T}_{0}\right), \quad \mathrm{A}_{5}=$ 0.8974794 , and $\mathrm{A}_{6}=\mathrm{a}_{6} \mathrm{~T} ; \mathrm{a}_{6}=\left(9.896161 / \mathrm{T}_{0}\right)$. Where $\mathrm{T}$ is the temperature of the material in ${ }^{\circ} \mathrm{C}, \mathrm{T}_{0}$ is the room temperature and is considered $25{ }^{\circ} \mathrm{C}$. Then the differentiation of Eq. (1) w. r. t operating wavelength $\lambda$ yields:

$$
\frac{d n}{d \lambda}=-(\lambda / n) \cdot\left[\frac{A_{1} A_{2}^{2}}{\left(\lambda^{2}-A_{2}^{2}\right)^{2}}+\frac{A_{3} A_{4}^{2}}{\left(\lambda^{2}-A_{4}^{2}\right)^{2}}+\frac{A_{5} A_{6}^{2}}{\left(\lambda^{2}-A_{6}^{2}\right)^{2}}\right]
$$


The differentiation of Eq. (1) w. r. $\mathrm{t}$ T gives:

$$
\frac{d n}{d T}=\left(\lambda^{2} / n\right) \cdot\left[\frac{A_{1} A_{2} a_{2}}{\left(\lambda^{2}-A_{2}^{2}\right)^{2}}+\frac{A_{3} A_{4} a_{4}}{\left(\lambda^{2}-A_{4}^{2}\right)^{2}}+\frac{A_{5} A_{6} a_{6}}{\left(\lambda^{2}-A_{6}^{2}\right)^{2}}\right] \text { (3) }
$$

\section{B) LITHIUM NIOBATE $\left(\mathrm{LINBO}_{3}\right)$ BASED MATERIAL}

The refractive index of this waveguide is cast under the Sellemier equation as the following [9]:

$$
n^{2}=B_{1}+B_{2} M+\frac{B_{3}+B_{4} M}{\lambda^{2}-\left(B_{5}+B_{6} M\right)^{2}}+\frac{B_{7}+B_{8} M}{\lambda^{2}-B_{9}^{2}}-B_{10} \lambda^{2}(4)
$$

The set of parameters is dimensionally adjusted as: $\mathrm{B}_{1}=5.35583, \mathrm{~B}_{2}=4.629 \times 10^{-7}, \mathrm{~B}_{3}=0.100473, \mathrm{~B}_{4}=3.862 \times 10^{-}$ ${ }^{8}, \mathrm{~B}_{5}=0.20692, \mathrm{~B}_{6}=-0.89 \times 10^{-8}, \mathrm{~B}_{7}=100, \mathrm{~B}_{8}=2.657 \times 10^{-5}$, $\mathrm{B}_{9}=11.34927, \mathrm{~B}_{10}=0.015334$, and $\mathrm{M}=\left(\mathrm{T}-\mathrm{T}_{\mathrm{o}}\right) .(\mathrm{T}+570.82)$. Equation (4) can be simplified as:

$$
n^{2}=B_{12}+\frac{B_{34}}{\lambda^{2}-B_{56}{ }^{2}}+\frac{B_{78}}{\lambda^{2}-B_{9}{ }^{2}}-B_{10} \lambda^{2}
$$

Where $\mathrm{B}_{12}=\mathrm{B}_{1}+\left(\mathrm{B}_{2} \mathrm{M}\right), \quad \mathrm{B}_{34}=\mathrm{B}_{3}+\left(\mathrm{B}_{4} \mathrm{M}\right) ; \quad \mathrm{B}_{56}=\mathrm{B}_{5}+\left(\mathrm{B}_{6} \mathrm{M}\right)$, and $B_{78}=B_{7}+\left(B_{8} M\right)$. Differentiation of Eq. (5) w. r. $t \lambda$ yields:

$$
\frac{d n}{d \lambda}=-(\lambda / n)\left[\frac{B_{34}}{\left(\lambda^{2}-B_{56}{ }^{2}\right)^{2}}+\frac{B_{78}}{\left(\lambda^{2}-B_{9}{ }^{2}\right)^{2}}+B_{10}\right]
$$

The differentiation of Eq. (5) w. r. $\mathrm{t}$ T gives:

$$
\frac{d n}{d T}=\frac{(d M / d T)}{2 n}\left[B_{2}+\frac{B_{4}\left(\lambda^{2}-B_{56}{ }^{2}\right)+\left(2 B_{6} B_{34} B_{56}\right)}{\left(\lambda^{2}-B_{56}{ }^{2}\right)^{2}}+\frac{B_{8}}{\left(\lambda^{2}-B_{9}{ }^{2}\right)}\right] \text { (7) }
$$

Where $(\mathrm{dM} / \mathrm{dT})=2 \mathrm{~T}+\left(570.82-\mathrm{T}_{\mathrm{o}}\right)$.

\section{C) GALlium ALUMinum ARSENIDE (GA(1-X)AL(X)AS) BASED MATERIAL}

Parameters required to characterize the temperature and operating wavelength dependence of the refractiveindex, where Sellmeier equation is under the form of [10]:

$$
n^{2}=C_{1}+\frac{C_{2}}{\lambda^{2}-C_{3}}-C_{4} \lambda^{2}
$$

The set of parameters is recast and dimensionally adjusted as [8]: $\mathrm{C}_{1}=10.906-2.92 \mathrm{x}, \mathrm{C}_{2}=0.97501, \mathrm{C}_{3}=\mathrm{c}_{3} \mathrm{~T}^{2}$; $\mathrm{c}_{3}=\left(0.52886-0.735 \mathrm{x} / \mathrm{T}_{\mathrm{o}}\right)^{2}$, for $\mathrm{x}<0.36$. And $\mathrm{C}_{4}=\mathrm{c}_{4}$ $\left(0.93721+\quad 2.0857 \times 10^{-4} \mathrm{~T}\right) ; \quad \mathrm{c}_{4}=0.002467(1.14 \mathrm{x}+1)$. Differentiation of Eq. (8) w. r. t $\lambda$ gives:

$$
\frac{d n}{d \lambda}=-(\lambda / n)\left[\frac{C_{2}}{\left(\lambda^{2}-C_{3}\right)^{2}}+C_{4}\right]
$$

The differentiation of Eq. (8) w. r. t T gives:

$$
\frac{d n}{d T}=(1 / 2 n)\left[\frac{2 c_{3} C_{2} T}{\left(\lambda^{2}-C_{3}\right)^{2}}-\left(2.0857 \times 10^{-4} c_{4} \lambda^{2}\right)\right]
$$

\section{2. OPERATING PARAMETERS OF AWG}

We expressed the corresponding grating order a function of operating wavelength range according to its band applications for a certain spectrum range as [11]:

$$
m=\frac{\lambda}{\lambda_{f}-\lambda},
$$

Where $\mathrm{m}$ is the diffraction order, $\lambda$ is the operating wavelength, $\lambda_{\mathrm{f}}$ is the final wavelength. The diffraction order is an important parameter. Once the diffraction order $\mathrm{m}$ is determined, some other parameters of the AWG device are also determined, such as the length difference of adjacent waveguides, focal length of the slab optical waveguide, free spectral range, maximum number of input/output wavelength channels, and number of the arrayed waveguides. The path length difference between adjacent arrayed optical waveguides $\Delta \mathrm{L}$ is given by [12]:

$$
\Delta L=\frac{m \lambda_{0}}{n},
$$

Where, $\mathrm{n}$ is the refractive-index of $\mathrm{AWG}$, and $\lambda_{0}$ is the center wavelength of the arrayed waveguide in $\mu \mathrm{m}$. The focal length of slab waveguide $\left(L_{f}\right)$ is given by the following equation [12]:

$$
L_{f}=\frac{n_{s} d^{2} n}{m \Delta \lambda n_{g}},
$$

Where $\mathrm{n}_{\mathrm{s}}$ is the effective index of the slab waveguide, $\mathrm{d}$ is the pitch length of adjacent input/output channels and arrayed waveguides in $\mu \mathrm{m}, \Delta \lambda$ is the wavelength channel spacing in $\mathrm{nm}$, and $\mathrm{n}_{\mathrm{g}}$ is the group refractive index and is given as the following:

$$
n_{g}=n-\lambda_{0} \frac{d n}{d \lambda},
$$

An important property of the AWG is the free spectral range (FSR), also known as the demu ltip le xer periodicity. This periodicity is due to the fact that constructive interface at the output free spectral range or region can occur for a number of wavelengths. The free spectral range denotes the wavelength and frequency spacing between the maximum of the interface pattern because of the periodic characteristic of the AWG transfer function, and can be [12]:

$$
F S R=\frac{\lambda_{0} n}{m n_{g}},
$$

The maximum number of I/O wavelength channels $\mathrm{N}_{\max }$ depends on the FSR. The bandwidth of the multiplexed light, that is $\mathrm{N}_{\max } \Delta \lambda$ must be narrow than an FSR to prevent the overlapping of orders in the spectral region. Therefore, $\mathrm{N}_{\max }$ can be derived as follows [12]:

$$
N_{\max }=\text { int } \operatorname{eger}\left(\frac{F S R}{\Delta \lambda}\right),
$$

The number of the arrayed waveguides $\mathrm{P}$ is not a dominant parameter in the AWG design because the wavelength channel spacing $\Delta \lambda$ and maximum number of wavelength channels $\mathrm{N}_{\max }$ do not depend on it. Generally, $P$ is selected so that the number of the arrayed waveguides is sufficient to make the numerical aperture (NA), in which they form a greater number than the input/output waveguides, such that almost all the light diffracted into the free space region is collected by the array aperture. As a general rule, this number should be bigger than four times the number of wavelength channels $[13,14]$ :

$$
P=4 \text { int } \operatorname{eger}\left(\frac{F S R}{\Delta \lambda}\right) \text {. }
$$




\section{SIMULATION RESULTS AND DISCUSSIONS}

We have investigated the new materials based arrayed waveguide grating optical devices for multi-band multiplexing/demultiplexing applications. In fact, the employed software computed the variables under the following operating parameters, for temperature variations from $\mathrm{T}=25{ }^{\circ} \mathrm{C}$ to $\mathrm{T}=65{ }^{\circ} \mathrm{C}$. and also under different channel spacing $\Delta \lambda=0.4 \mathrm{~nm}$ and $\Delta \lambda=0.2 \mathrm{~nm}$.

Table1. Typical values of operating parameters in proposed model [13].

\begin{tabular}{|c|c|c|}
\hline Operating parameter & Symbol & Value \\
\hline Final wavelength & $\lambda_{\mathrm{f}}$ & $1.65 \mu \mathrm{m}$ \\
\hline Center wavelength & $\lambda_{0}$ & $1.55 \mu \mathrm{m}$ \\
\hline Pitch length & $\mathrm{d}$ & $15 \mu \mathrm{m}$ \\
\hline Slab refractive-index & $\mathrm{n}_{\mathrm{s}}$ & 3.06 \\
\hline
\end{tabular}

A) Variations of the diffraction order

Variations of the diffraction order $m$ are investigated against variations of the controlling set of parameters as displayed in Fig. 3 for all materials used in our research $\left(\mathrm{SiO}_{2}, \mathrm{LiNbO}_{3}, \mathrm{Ga}_{(1-\mathrm{x})} \mathrm{Al}_{\mathrm{X}} \mathrm{As}\right)$. This figure clarifies that while operating wavelength $\lambda$ increases, this leads to diffraction order $\mathrm{m}$ also increases at the assumed set of the operating parameters .

\section{B) Variations of the path length difference between} adjacent arrayed waveguides

Variations of $\Delta \mathrm{L}$ are investigated against variations of the controlling set of parameters as displayed in Fig. 4 for all material used in our research $\left(\mathrm{SiO}_{2}, \mathrm{LiNbO}_{3}, \mathrm{Ga}_{(1-}\right.$ ${ }_{x)} \mathrm{Al}_{\mathrm{x}} \mathrm{As}$ ). This figure clarifies the following results:

i. As diffraction order $\mathrm{m}$ increases this results in path length difference $\Delta \mathrm{L}$ also increases for all materials based conventional AWG.

ii. For certain value of diffraction order $m$, the value of path length difference $\Delta \mathrm{L}$ for $\mathrm{SiO}_{2}$ is the largest than $\mathrm{LiNbO}_{3}$ and $\mathrm{Ga}_{(1-\mathrm{x})} \mathrm{Al}_{\mathrm{x}} \mathrm{As}$.

\section{C)Variations of the free spectral range}

Variations of FSR, are investigated against variations of the set of parameters as displayed in Figs. (5, 6) for all materials used in research $\left(\mathrm{SiO}_{2}, \mathrm{LiNbO}_{3}, \mathrm{Ga}_{(1-}\right.$ ${ }_{\mathrm{x})} \mathrm{Al}_{\mathrm{x}} \mathrm{As}$ ). These figures clarify the following results:

i. As diffraction order $m$ increases, FSR decreases for all materials based conventional AWG.

ii. For certain value of diffraction order $m$, value of FSR for $\mathrm{SiO}_{2}$ is larger than $\mathrm{LiNbO}_{3}$ and $\mathrm{Ga}(1-$ x)AlxAs.

iii. As ambient te mperature $\mathrm{T}$ increases, FSR decreases for all materials, but in the case of using $\mathrm{Ga}(1-$ x)AlxAs there was significant decreasing.

\section{D) Variations of the path focal length of slab waveguide}

Variations of path focal length $\mathrm{L}_{\mathrm{f}}$, are investigated against variations of the controlling set of parameters as displayed in Figs. (7-10) for all material used in our research $\left(\mathrm{SiO}_{2}, \mathrm{LiNbO}_{3}, \mathrm{Ga}_{(1-\mathrm{x})} \mathrm{Al}_{\mathrm{x}} \mathrm{As}\right)$. These figures clarify the following results: i. As diffraction order $\mathrm{m}$ increases, this results in decreasing of path focal length of slab waveguide for all materials based conventional AWG.

ii. For certain value of diffraction order $m$, value of path focal length of slab waveguide for $\mathrm{SiO}_{2}$ is the largest than $\mathrm{LiNbO}_{3}$ and $\mathrm{Ga}_{(1-\mathrm{x})} \mathrm{Al}_{\mathrm{X}} \mathrm{As}$.

iii. As ambient temperature $\mathrm{T}$ increases, this leads to decrease in path focal length for all materials, but in the case of using $\mathrm{Ga}_{(1-\mathrm{x})} \mathrm{Al}_{\mathrm{x}} \mathrm{As}$ there was significant decreasing.

iv. As channel spacing $\Delta \lambda$ decreases, this results in increasing path focal length of slab waveguide for all materials based conventional AWG.

E) Variations of maximum number of $\mathrm{I} O \mathrm{O}$ wavelength channels

Variations of $\mathrm{N}_{\max }$, are investigated against variations of the assumed set of parameters as displayed in Figs. (11-14) for all materials based conventional AWG devices in our research $\left(\mathrm{SiO}_{2}, \mathrm{LiNbO}_{3}, \mathrm{Ga}_{(1-\mathrm{x})} \mathrm{Al} l_{\mathrm{X}} \mathrm{As}\right)$. These figures clarify the following results:

i. As diffraction order $\mathrm{m}$ increases, this results in maximum number of trans mitted channels $\mathrm{N}_{\max }$ decreases for all materials based conventional AWG devices.

ii. For certain value of diffraction order $\mathrm{m}, \mathrm{SiO}_{2}$ based AWG presents the largest number of transmitted channels than $\mathrm{LiNbO}_{3}$ and $\mathrm{Ga}_{(1-\mathrm{x})} \mathrm{Al}_{\mathrm{x}} \mathrm{As}$.

iii. As ambient temperature $\mathrm{T}$ increases, this leads to decrease in number of transmitted channels $\mathrm{N}_{\max }$ for all materials, but in the case of using $\mathrm{Ga}_{(1-\mathrm{x})} \mathrm{Al}_{\mathrm{x}} \mathrm{As}$, there was significant decreasing.

iv. As channel spacing $\Delta \lambda$ decreases, this results in increasing number of transmitted channels for all materials based conventional AWG.

F) Variations of number of the arrayed waveguides Variations of $\mathrm{P}$, are investigated against variations of the controlling set of parameters as displayed in Figs. (15-18) for all materials used in our research $\left(\mathrm{SiO}_{2}\right.$, $\left.\mathrm{LiNbO}_{3}, \quad \mathrm{Ga}_{(1-\mathrm{x})} \mathrm{Al}_{\mathrm{x}} \mathrm{As}\right)$. These figures clarify the following results:

i. As diffraction order $\mathrm{m}$ increases, this leads to decrease in number of arrayed waveguides for all used materials.

ii. For certain value of diffraction order $m$, number of arrayed waveguides for $\mathrm{SiO}_{2}$ is the largest than $\mathrm{LiNbO}_{3}$ and $\mathrm{Ga}_{(1-\mathrm{x})} \mathrm{Al}_{\mathrm{x}} \mathrm{As}$

iii. As ambient temperature $\mathrm{T}$ increases, this results in decreasing number of arrayed waveguides for all materials, but in case of using $\mathrm{Ga}_{(1-\mathrm{x})} \mathrm{Al}_{\mathrm{x}} \mathrm{As}$ there was significant decreasing. 


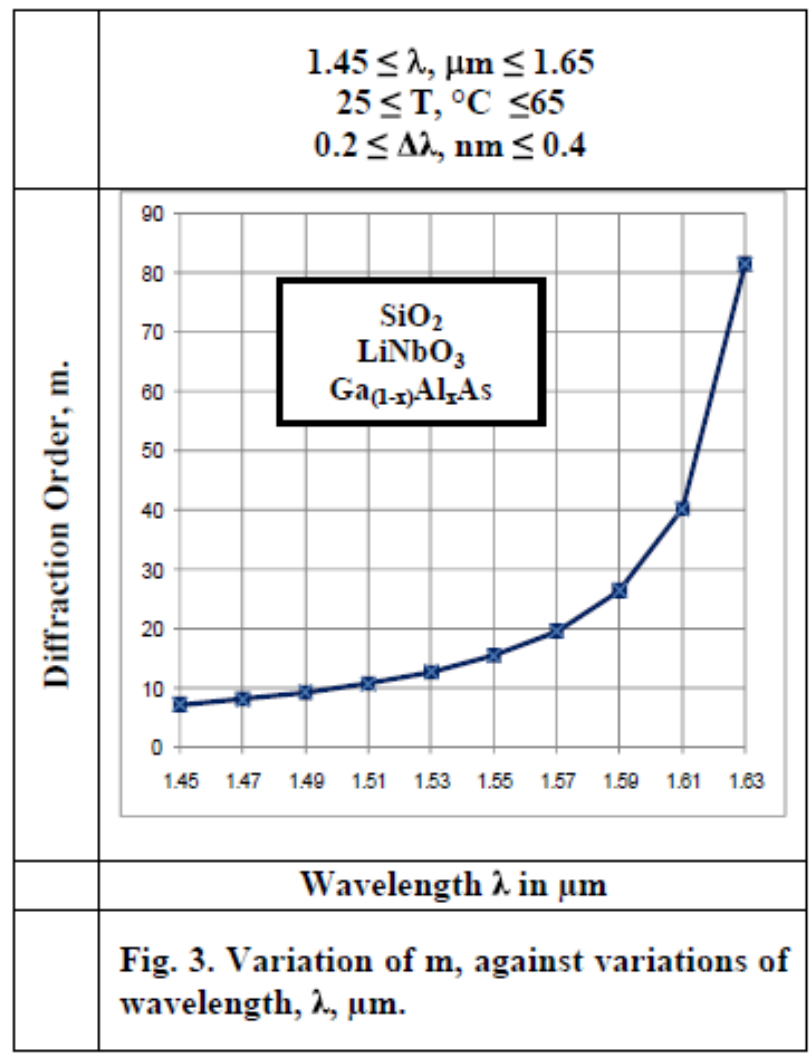

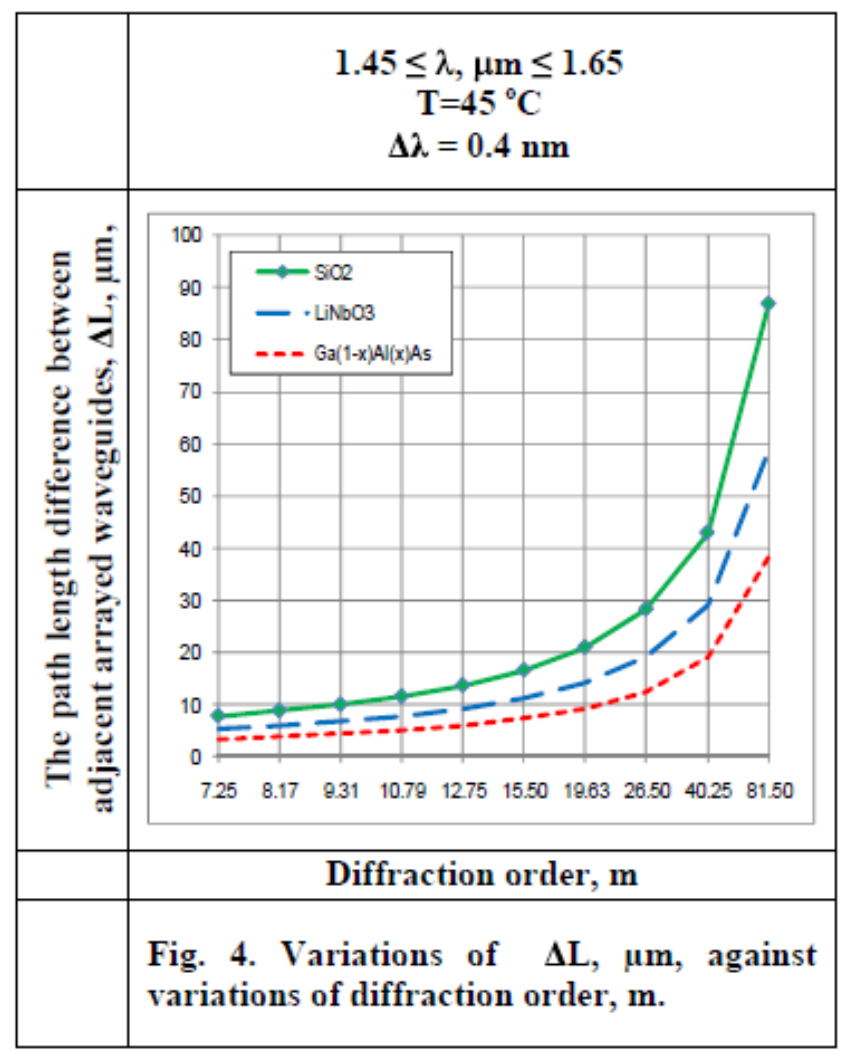

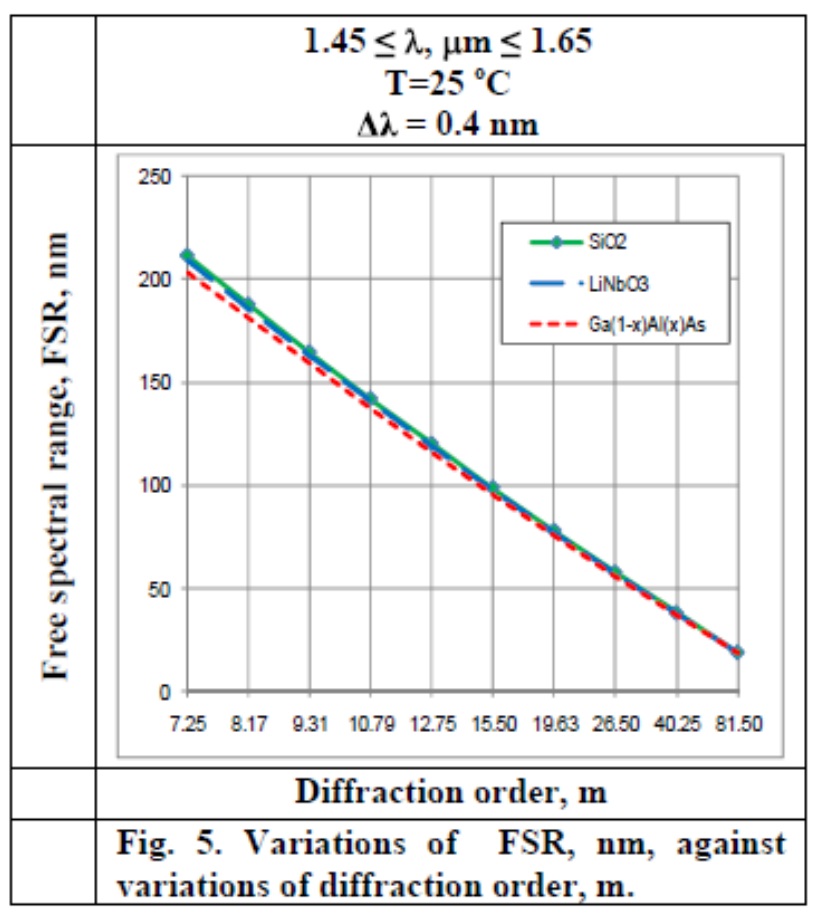

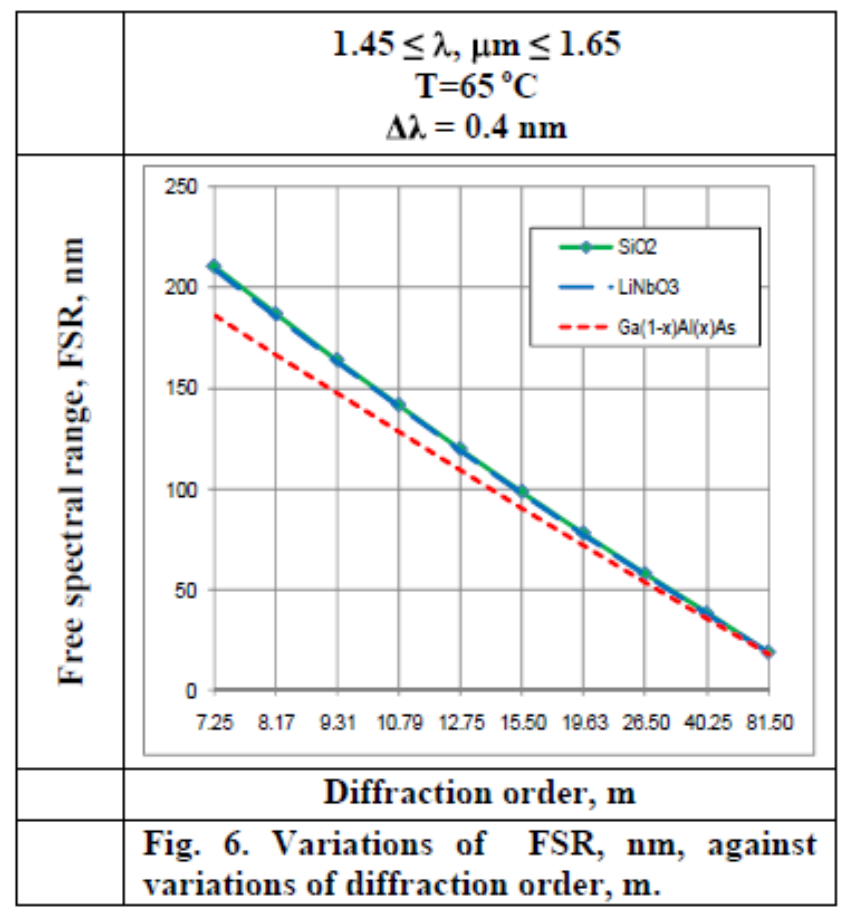



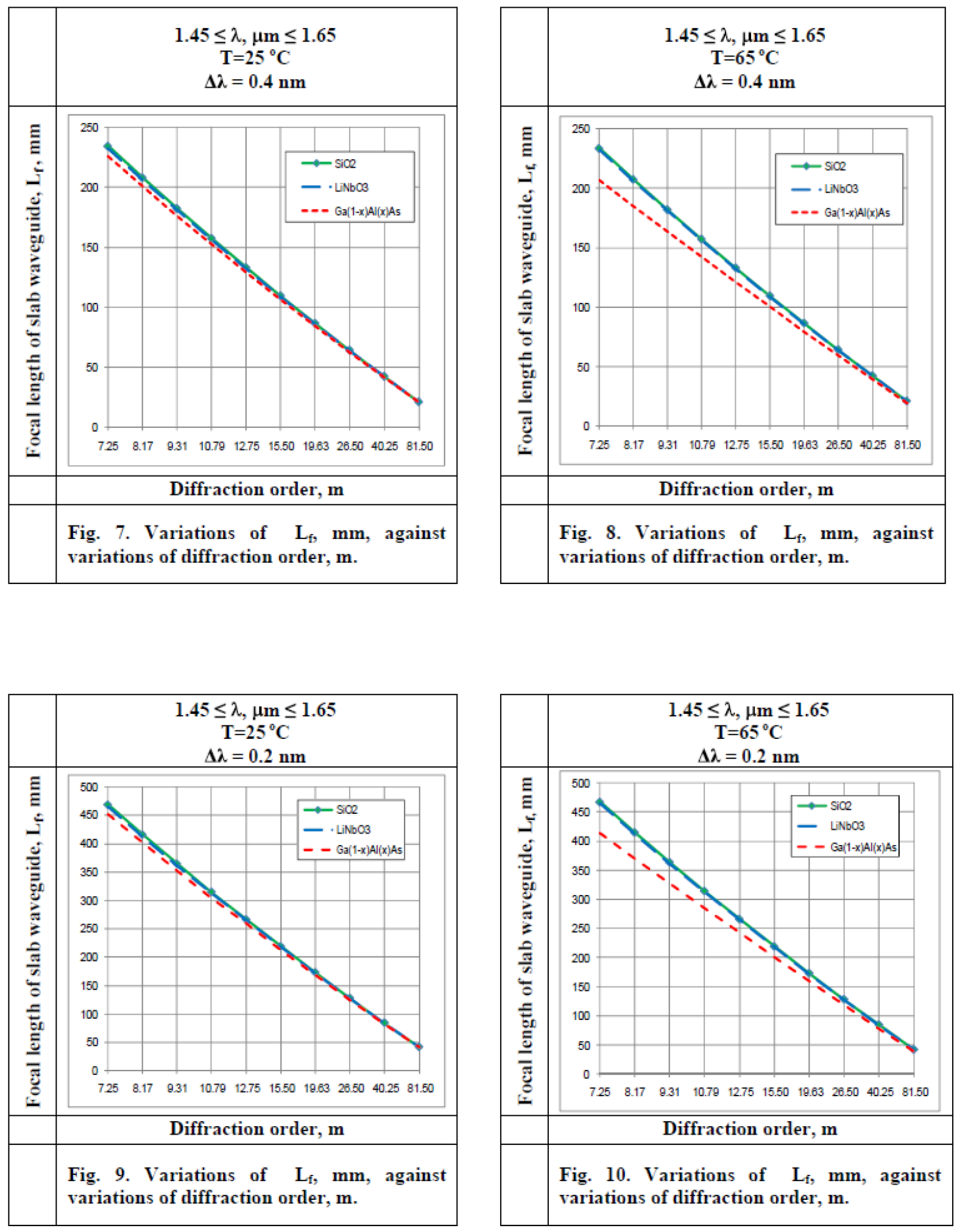

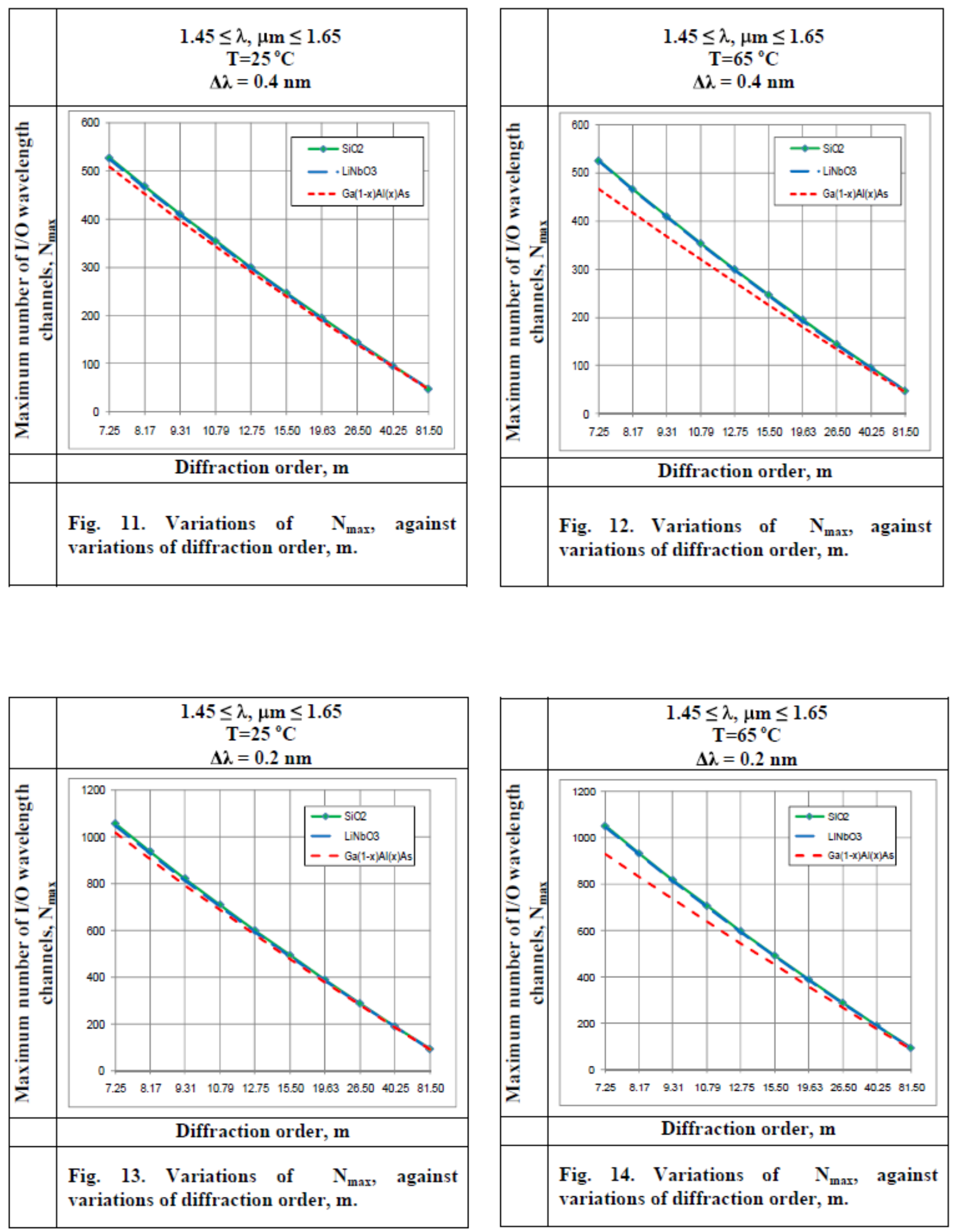

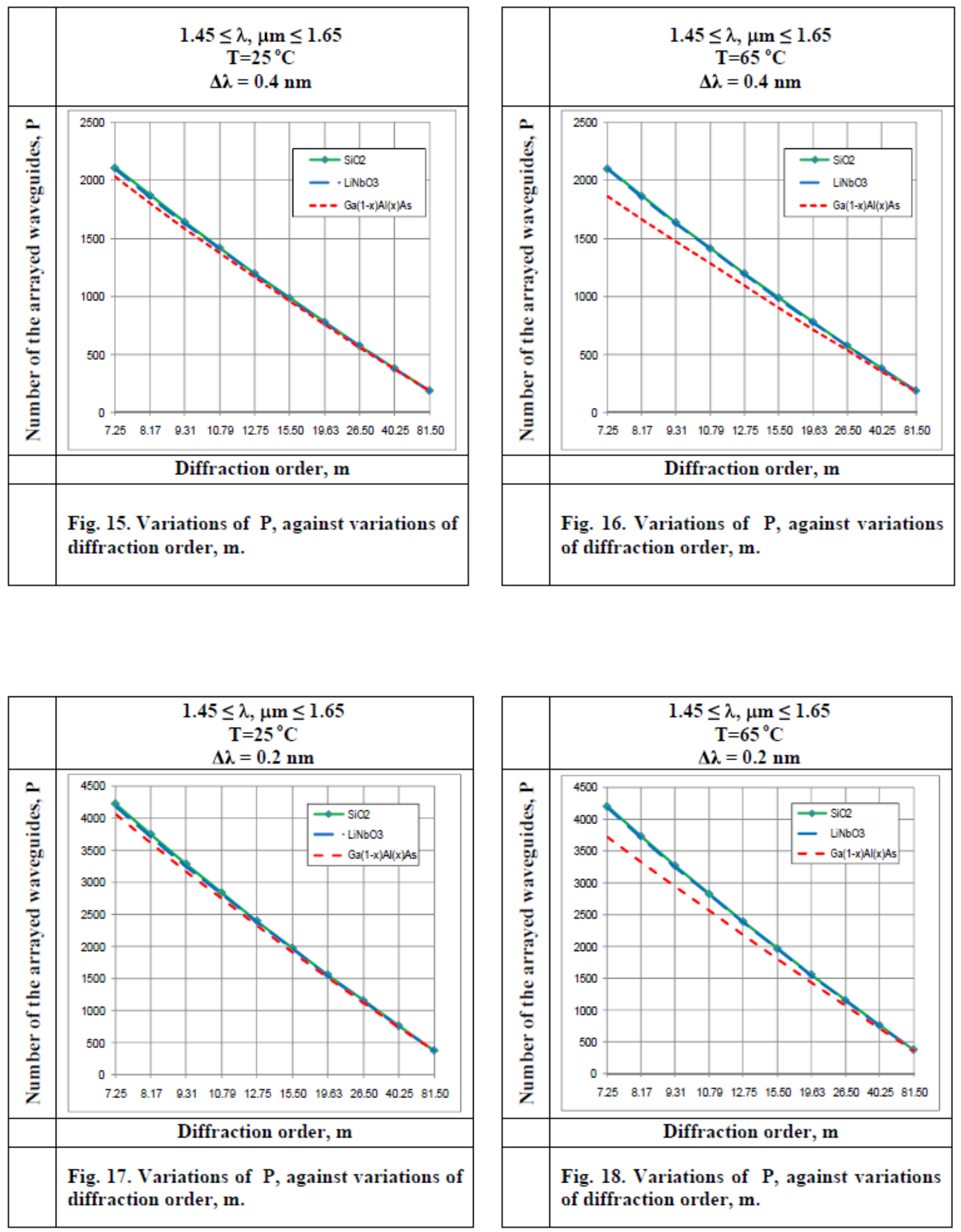

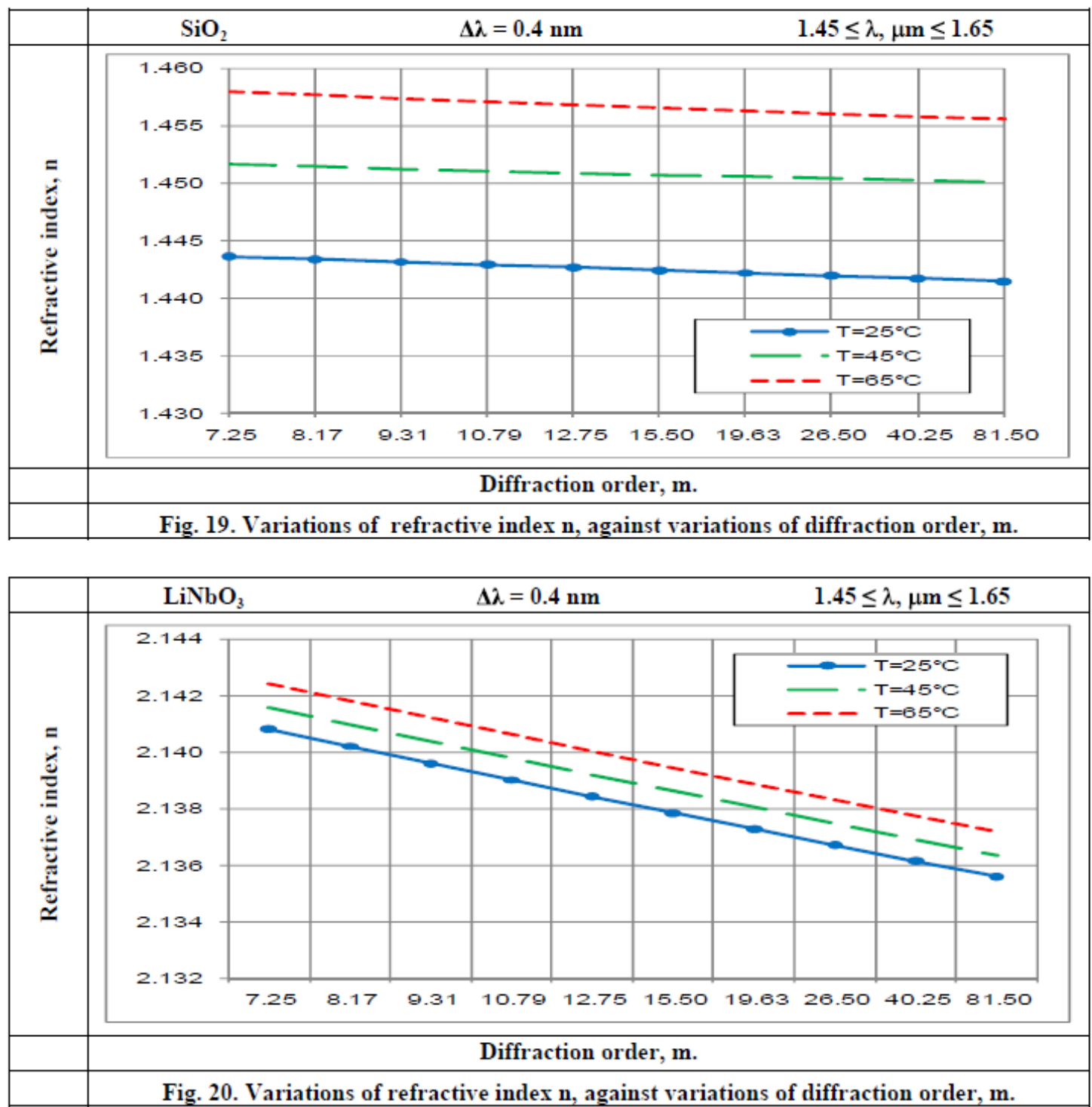

Fig. 20. Variations of refractive index $\mathbf{n}$, against variations of diffraction order, $m$.

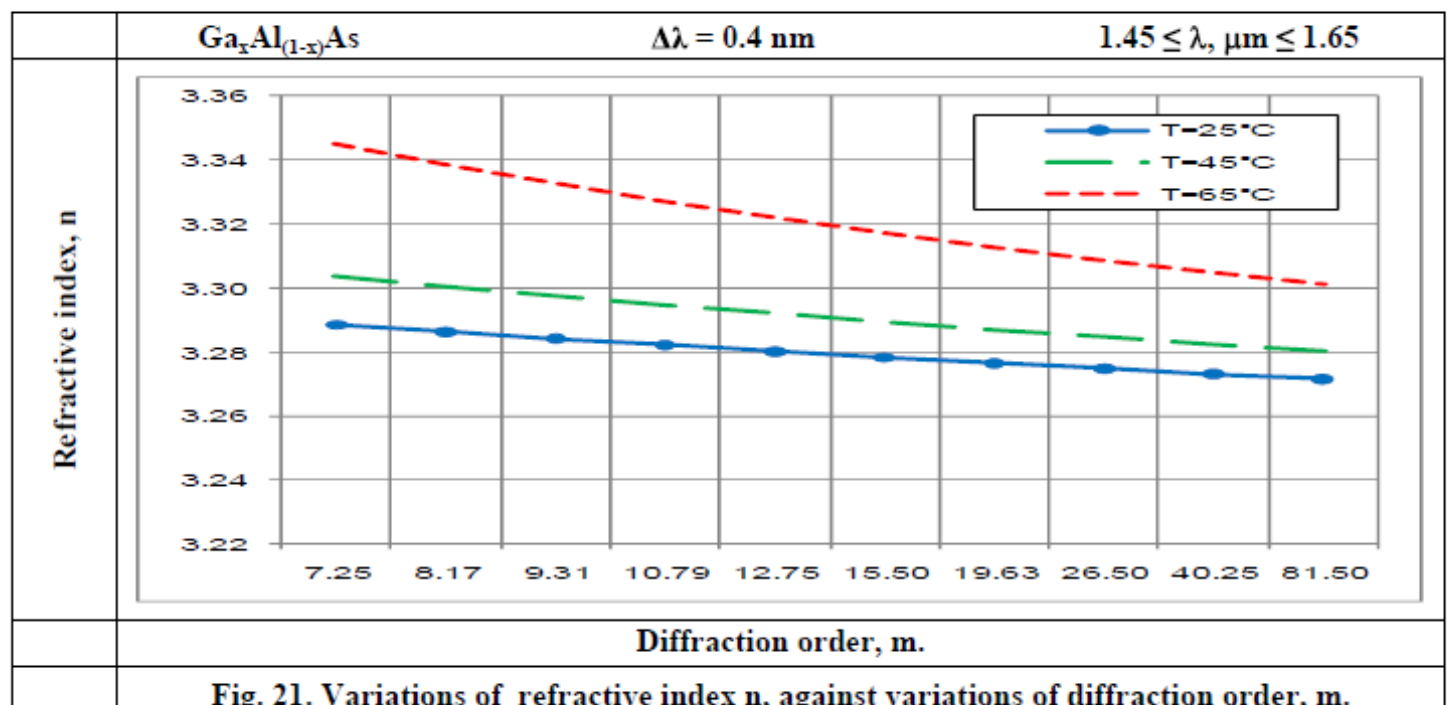

Fig. 21. Variations of refractive index $\mathbf{n}$, against variations of diffraction order, $\mathbf{m}$. 

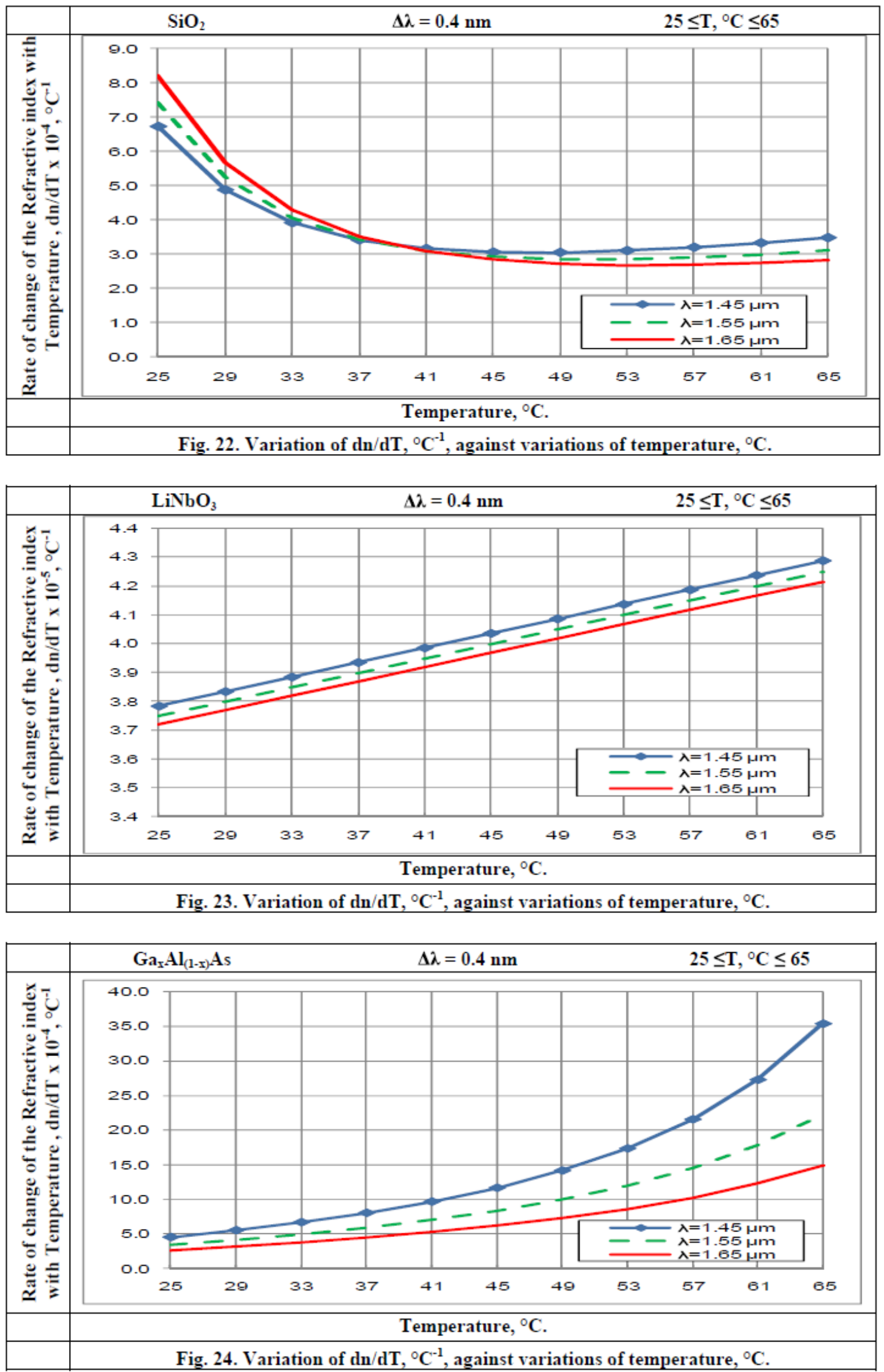

iv. As channel spacing $\Delta \lambda$ decreases, this leads to increase number of arrayed waveguides for all use materials. 


\section{G) Variations of the refractive index}

Variations of refractive-index $n$, are investigated against variations of the controlling set of parameters as displayed in Figs. (19-21) for all materials based conventional AWG devices $\left(\mathrm{SiO}_{2}, \mathrm{LiNbO}_{3}, \mathrm{Ga}_{(1-\mathrm{x})} \mathrm{Al} \mathrm{x}_{\mathrm{x}} \mathrm{As}\right)$. These figures clarify the following results:

i. As diffraction order $m$ increases, refractive index $n$ decreases for all used materials.

ii. For certain value of diffraction order $m$ and ambient temperature $\mathrm{T}$, the refractive index $\mathrm{n}$ for $\mathrm{SiO}_{2}$ is the lowest than $\mathrm{LiNbO}_{3}$ and $\mathrm{Ga}_{(1-\mathrm{x})} \mathrm{Al}_{\mathrm{X}} \mathrm{As}$.

iii. As ambient temperature $\mathrm{T}$ increases, refractive index $\mathrm{n}$ increases for all materials based conventional AWG.

\section{H) Variations of $\mathbf{d n} / \mathrm{dT}$}

Variations of $\mathrm{dn} / \mathrm{dT}$ are investigated against variations of the controlling set of parameters as displayed in Figs. (22-24) for all materials based conventional AWG devices $\left(\mathrm{SiO}_{2}, \mathrm{LiNbO}_{3}, \mathrm{Ga}_{(1-\mathrm{x})} \mathrm{Al} \mathrm{x}_{\mathrm{x}} \mathrm{As}\right)$. These figures clarify the following results:

a) Within the effect of ambient temperature:

i. For $\mathrm{SiO}_{2}$ : As ambient temperature $\mathrm{T}$ increases, rate of change of refractive-index with respect to temperature $\mathrm{dn} / \mathrm{dT}$ decreases exponentially until reach to approximate value of $39{ }^{\circ} \mathrm{C}$, as well as there is slightly decreasing until reaches to approximate value of $51^{\circ} \mathrm{C}$, and after that there is exponential increasing.

ii. For $\mathrm{LiNbO}_{3}$ : As ambient temperature $\mathrm{T}$ increases, rate of change of refractive-index with respect to temperature $\mathrm{dn} / \mathrm{dT}$ increases linearly.

iii. For $\mathrm{Ga}(1-\mathrm{x}) \mathrm{AlxAs}$ : As ambient temperature $\mathrm{T}$ increases, rate of change of refractive-index with respect to temperature $\mathrm{dn} / \mathrm{dT}$ increases exponentially.

b)Within the effect of wavelength at certain temperature:

i. For $\mathrm{SiO}_{2}$ : As operating signal wavelength $\lambda$ increases, $\mathrm{dn} / \mathrm{dT}$ also increases exponentially until reaches to approximate value of $39{ }^{\circ} \mathrm{C}$, and after that as $\lambda$ increases, $\mathrm{dn} / \mathrm{dT}$ decreases exponentially.

ii. For both $\mathrm{LiNbO}_{3} \& \mathrm{Ga}_{(1-\mathrm{x})} \mathrm{Al}_{\mathrm{x}} \mathrm{As}$ : As operating wavelength $\lambda$ increases, $\mathrm{dn} / \mathrm{dT}$ decreases.

\section{Conclusions}

In a summary, we have investigated the ultra wide wavelength multiplexing/demultiplexing conventional AWG for multi band applications. It is observed that the increased diffraction order, the decreased refractive index for all materials based AWG devices. We have indicated that the increased of both ambient temperature and diffraction order, the decreased number of arrayed waveguides. As well as the decreased of ambient temperature, channel spacing, and diffraction order, this results in increasing of number of input/output wavelength channels. Moreover we have observed that $\mathrm{SiO}_{2}$ based material for $\mathrm{AWG}$ devices presents the highest number of trans mitted channels than the other materials based conventional AWG. So $\mathrm{SiO}_{2}$ material based for conventional AWG is the best candidate for core material than the other materials used in our research.

\section{REFERENCES}

[1] Abd El-Naser A. Mohammed, Gaber E. S. M. El-Abyad, Abd El-Fattah A. Saad, and Ahmed Nabih Zaki Rashed, "High Transmission Bit Rate of A thermal Arrayed Waveguide Grating (AWG) Module in Passive Optical Networks," IJCSIS International Journal of Computer Science and Information Security, Vol. 1, No. 1, pp. 13-22, May 2009.

[2] H. Kosek, Y. He, X. Gu, and X. Fernando, “All Optical Demultiplexing Closely Spaced Multimedia Radio Over Fiber Signals Using Subpicometer Fiber Bragg Grating," Journal of Lightwave Technology, Vol. 13, No.4, pp. 191200, 2006.

[3] J. Ma, J. Yu, C. Yu, X. Xin, J. Zeng, and L. Chen, "Fiber Dispersion Influence on Transmission of the Optical Millimeter Waves Generated Using LN-MZM Intensity Modulation," J. of Ligthwave Technol., Vol. 25, No. 2, pp. 3244-3256, 2007.

[4] Yang, Y., C. Lou, H. Zhou, J. Wang, and Y. Gao, "Simple pulse compression scheme based on filtering self-phase modulation broadened spectrum and its application in an optical time-division multiplexing systems," Appl. Opt., Vol. 45, 7524-7528, 2006.

[5] S. Sawetanshumala, and S. Konar, "Propagation of a mixture of Modes of A laser Beam in A medium With Securable Nonlinearity," Journal of Electromagnetic Waves and Applications, Vol. 20, No. 1, pp.65-77, 2006.

[6] R. Gangwar, S. P. Singh, and N. Singh, "Soliton Based Optical Communication," Progress In Electromagnetics Research, PIER Vol. 74, No.3, pp. 157-166, 2007.

[7] A. Sangeetha , S. K. Sudheer, and K. Anusudha, "Performance Analysis of NRZ, RZ, and Chirped RZ Transmission Formats in Dispersion Managed $10 \mathrm{Gbit} / \mathrm{sec}$ Long Haul WDM Lightwave Systems," International Journal of Recent Trends in Engineering, Vol. 1, No. 4, pp. 103-105, May 2009.

[8] ITU-T, series G, "General aspects of optical fiber cable," pp. 10-11, 2009.

[9] D. H. Jundt, “Temperature-dependent Sellmeier equation for the index of refraction, $\mathrm{n}_{\mathrm{e}}$, in congruent lithium niobate," Optics Letters, Vol. 22, No. 20, pp.1553-1555, 1997.

[10] Osama A. Oraby, "Propagation of An Electromagnetic Beams in Nonlinear Dielectric Slab Wave Guides," Minufiy a Journal of Electronic En gineering Research, Vol. 16, No. 1, pp. 27-44, 2006.

[11] J. Qiao, F. Zhao, J. W. Horwitz, R. T. Chen, and W. W. Morey "A thermalized Low Loss Echelle Grating Based Multimode Dense Wavelength Division Multiplexer," J. Applied Optics, Vol. 41, No. 31, pp.6567-6575, 2002.

[12] Abd El-Naser A. Mohammed, Abd El-Fattah A. Saad, and Ahmed Nabih Zaki Rashed, "Matrices of the Thermal and Spectral Variations for the fabrication Materials Based Arrayed Waveguide Grating Devices," International Journal of Physical Sciences, Vol. 4, No. 4, pp. 205-211, April 2009.

[13] Abd El-Naser A. Mohammed, Abd El-Fattah A. Saad, and Ahmed Nabih Zaki Rashed, "Estimated Optimization Parameters of Arrayed Waveguide Grating (AWG) for CBand Applications," International Journal of Physical Sciences, Vol. 4, No. 4, pp. 149-155, April 2009.

[14] Abd El-Naser A. Mohammed, Abd El-Fattah A. Saad, and Ahmed Nabih Zaki Rashed, "Thermal Sensitivity 
Coefficients of the Fabrication Materials Based A thermal Arrayed Waveguide Grating (AWG) in Wide Area Dense Wavelength Division Multiplexing Optical Networks," International Journal of Engineering and Technology (IJET), Vol. 1, No. 2, pp. 131-139, June 2009.

\section{Author's Profile}

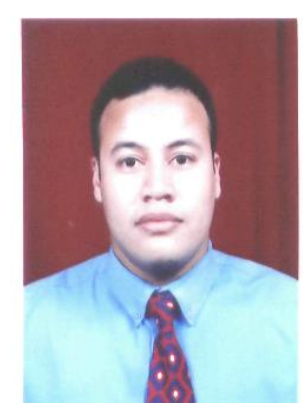

Dr. Ahmed Nabih Zaki Rashed was born in Menouf city, Menoufia State, Egypt country in 23 July, 1976. Received the B.Sc., M.Sc., and Ph.D. scientific degrees in the Electronics and Electrical Communications Engineering Department from Faculty of Electronic Engineering, Menoufia University in 1999, 2005, and 2010 respectively. Currently, his job carrier is a scientific lecturer in Electronics and Electrical Communications Engineering Department, Faculty of Electronic Engineering, Menoufia university, Menouf. Postal Menouf city code: 32951, EGYPT.

His scientific master science thesis has focused on polymer fibers in optical access communication systems. Moreover his scientific Ph. D. thesis has focused on recent applications in linear or nonlinear passive or active in optical networks. His interesting research mainly focuses on transmission capacity, a data rate product and long transmission distances of passive and active optical communication networks, wireless communication, radio over fiber communication systems, and optical network security and management. He has published many high scientific research papers in high quality and technical international journals in the field of advanced communication systems, optoelectronic devices, and passive optical access communication networks. His areas of interest and experience in optical communication systems, advanced optical communication networks, wireless optical access networks, analog communication systems, optical filters and Sensors, digital communication systems, optoelectronics devices, and advanced material science, network management systems, multimedia data base, network security, encryption and optical access computing systems. As well as he is editorial board member in high academic scientific International research Journals. Moreover he is a reviewer member in high impact scientific research international journals in the field of electronics, electrical communication systems, optoelectronics, information technology and advanced optical communication systems and networks. His personal electronic mail ID (Email:ahmed_733@y ahoo.com).

How to cite this paper: Abd El-Naser A. Mohamed,Ahmed Nabih Zaki Rashed,Mahmoud M. A. Eid,"Ultra Wide Wavelength Multiplexing/Demultiplexing Conventional Arrayed Waveguide Grating (AWG) Devices for Multi Band Applications", International Journal of Intelligent Systems and Applications(IJISA), vol.4, no.2, pp.16-27, 2012. DOI: 10.5815/ijisa.2012.02.02 